\title{
Power System Stabilizer Application for Load Frequency Control in Hydro-Electric Power Plant
}

\author{
Ghazanfar Shahgholian \\ Department of Electrical Engineering, Najafabad Branch, Islamic Azad University, Najafabad, Isfahan, Iran
}

Email address:

shahgholian@iaun.ac.ir

To cite this article:

Ghazanfar Shahgholian. Power System Stabilizer Application for Load Frequency Control in Hydro-Electric Power Plant. International Journal of Theoretical and Applied Mathematics. Vol. 3, No. 4, 2017, pp. 148-157. doi: 10.11648/j.ijtam.20170304.14

Received: December 1, 2016; Accepted: January 12, 2017; Published: October 24, 2017

\begin{abstract}
Renewable energy provides 20\% of electricity generation worldwide. Hydroelectric power is the cheapest way to generate electricity today. It provides almost onefifth of the electricity in world. Hydropower is produced in more than 150 countries. The main objective of this paper is modelling and analysis of the effects of the power system stabilizer (PSS) for load frequency control (LFC) system in hydro-electric power plant to damp the frequency oscillations due to different load distributions. LFC is the mechanism by which the energy balance is maintained. PSS is used to increase the system positive damping. The results of small signal stability analysis have been represented employing eigenvalue as well as time domain response.
\end{abstract}

Keywords: Hydro-Electric Power Plant, Load Frequency Control, Eigenvalues Analysis

\section{Introduction}

Power quality is essential to optimize the performance of power system equipment $[1,2]$. In transmission of electrical energy, the active power and reactive power both between the production and consumption of power should be balanced, that this balance makes setting two important parameters of voltage and frequency $[3,4]$. Stay on voltage and frequency at the time of performance in the standard range causes improve the quality of the electric power system. Therefore, a control system to remove the effects of sudden changes and momentary of electric power load and keep the voltage and frequency at the desired level is necessary [5]. Power delivered by the generator with input mechanical power by drivers such as steam turbines, water turbines and gas turbine or diesel engine is controlled [6,7]. During oscillations in a power system, mechanical torque by opening and closing the valve feeding the turbines varies. These changes are rapid oscillation damping. In a power system when power demand is suddenly change, regional frequency and power exchange in tie-lines both are subject to change $[8,9]$. The load deman$\mathrm{d}$ varies is reflected by a change in frequency in the power system and a change in the generator electrical torque output. Active power balance will remain constant system frequency and imbalance can directly affect the frequency and speed of the generator, thus applying load frequency control (LFC) in the power system is necessary $[10,11]$. The objective of the LFC is to satisfy the following requirements $[12,13]$ : (a) zero steady state errors in tie-line exchanges and frequency deviations, (b) optimal transient behaviors and (c) in steady state, the power generation levels should satisfy the optimal dispatch conditions. The flow of active power in a transmission system is influenced by different control actions. PSS and flexible ac transmission system (FACTS) devices can help the damping of power system oscillations and increase the system stability $[14,15]$. The basic function of a PSS is to add damping to the generator rotor oscillations by controlling its excitation using auxiliary stabilizing signals $[16,17]$.

Hydropower plant is produced due to the energy provided by moving or falling water. In order to meet the increasing demand for electricity, most of the countries give priority to its development, and many hydropower plants have been buiIt. The classification of hydro-electric power plants is shown in Figure $1[18,19]$. The classification of hydro power plants base on quantity are reservoir plants, pumped storage plants $[20,21]$ and run of river plants. Hydropower plants have essentially five major components. These are the storage reservoir, intake tunnel, surge tank, penstock, and hydro turbine.

Several control technique for LFC were proposed in the many papers $[22,23]$. A design technique based on optimal 
pole shift theory to control a low-head hydro power plant connected as a single machine to an infinite bus (SMIB) system is presented in [24], which a state-space model with two-input and two-output variables is considered. The prospective of parameter space methods for robust control and algorithm for a robust controller based a pole shifting adaptive control technique are presented in [25]. A step-bystep coordinated design procedure for PSS and automatic voltage regulator (AVR) in a strongly coupled system is described in [26], which the proposed design approach is useful small-signal complement to established large-signal transient simulation studies. An approach for the design of multiple power system stabilizers in two-area non reheat thermal system for three pre-defined cases is proposed in [27], which the optimal parameters of the PSS are obtained employing genetic algorithm using integral of time multiplied absolute value of the error criteria. A fractional order PID for single area LFC for all three types of turbines (non-reheated, reheated and hydro turbines) is designed in [28], which the optimization of controller parameters and robustness evaluation of the control technique is done on the basis of the integral error criterion. A PID tuning method based on the two-degree-of-freedom internal model control for LFC of power systems is presented in [29], which the method is applicable to power systems with non-reheated, reheated, and hydro turbines. The impact of interline power flow controller and redox flow batteries on an interconnected two-area multiple-unit thermal reheat power system in restructured environment is presented in [30]. In [31], the design and analysis of a robust PID controller for a hydraulic turbine generator governor using a frequency response technique are presented. The analysis of automatic generation control (AGC) of a two-area interconnected hydrothermal power system to damp the system frequency and tie-power oscillations by controlling the phase angle of thyristorcontrolled phase shifter (TCPS) in series with the tie-line has been investigated in [32], which gain settings of the integral controllers are optimized using integral squared error (ISE) technique by minimizing a quadratic performance index. A PID tuning technique using internal mode control for decentralized load frequency control in deregulated environment has been investigated in [33].

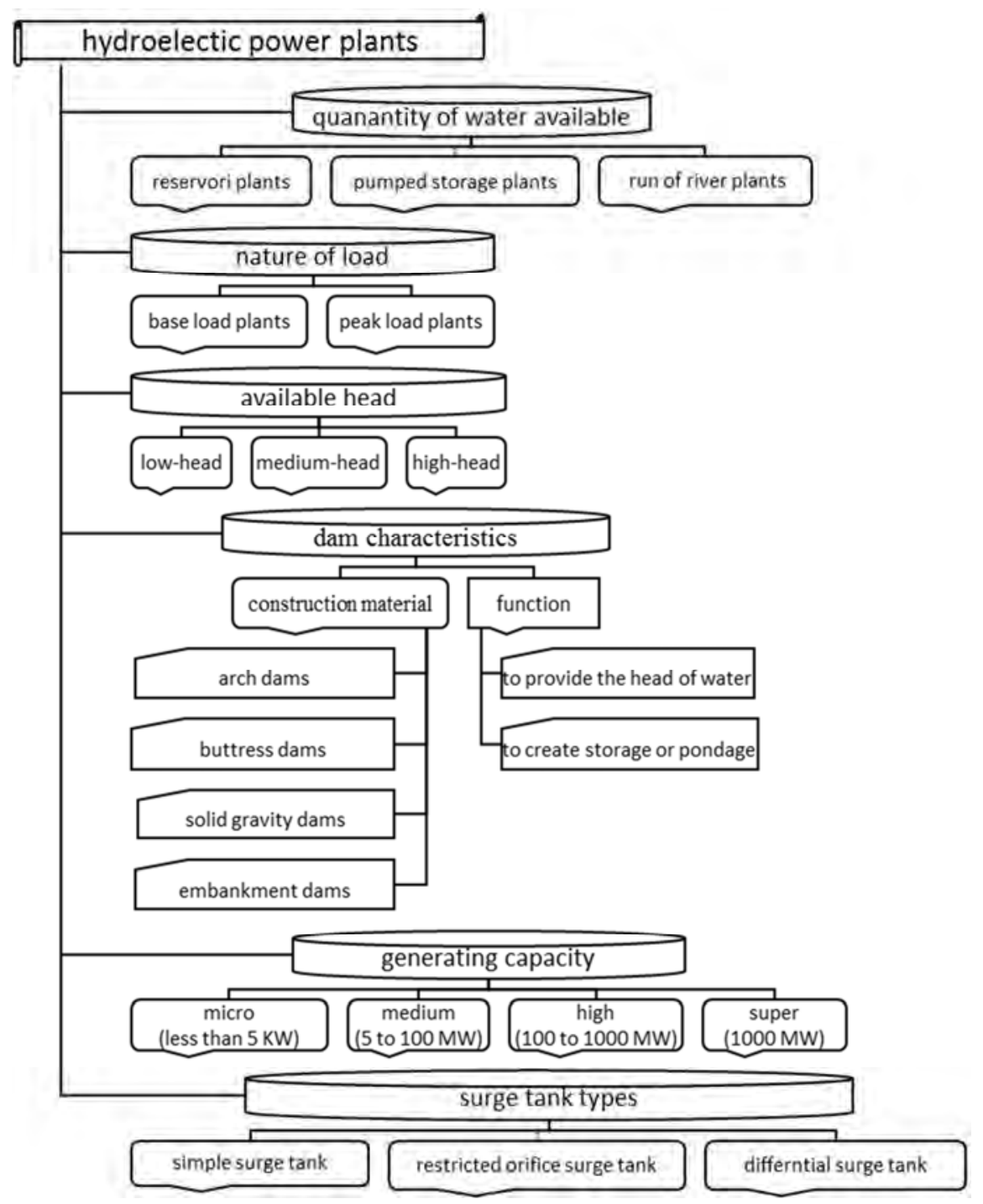

Figure 1. Showing the classification overview of hydroelectric power plants. 
According to change of active and reactive powers and relatively independent of each other always load frequency control systems and automatic voltage regulator (AVR) systems in power generation is needed to control the transient and steady state responses. This paper describes the applications of PSS on system dynamic performance in hydro power system for single area LFC. The parameters of PSS are optimally tuned to stabilize the system, increase system damping, and improve the steady-state frequency when the system is subjected to different disturbances. Eigenvalues analysis validates the performance of controller.

\section{Hydro Turbine}

In hydroelectric plant energy requirements is supplied by the potential energy of water behind a dam, which the energy produced depends on the volume of water behind the dam and the difference in height between the source and drain water from the dam. Hydroelectric power plant based on the height of water falling are divided into three groups: low head (less than $100 \mathrm{~m})$, the medium head $(30 \mathrm{~m}$ to $100 \mathrm{~m}$ ) and high head (greater than $100 \mathrm{~m}$ ) [34]. Hydro turbines composed of two types of impact and reaction, which changes in in power and structure of hydro turbines depends on the height of the water drop but has the same characteristic response [35]. With linear assumption the profile turbines and regardless of the pipe friction coefficient, the classic transfer function of an ideal hydro turbine no losses (the ratio of mechanical power to change valve position with the effect of changes in the water column nonelastic) is as follows [36]:

$$
G_{T}(s)=\frac{\Delta T_{M}(s)}{\Delta X_{G}(s)}=\frac{1-T_{W} s}{1+0.5 T_{W} s}
$$

$\Delta \mathrm{T}_{\mathrm{M}}$ is the normalized values of the change output mechanical torque of the turbine. The parameter $\mathrm{Tw}$ is the water starting time and is a function of the length of the penstock and other physical dimensions. $\Delta \mathrm{X}_{\mathrm{G}}$ is incremental change in gate position, which it for turbine comes from speed regulator and represents the valve opening. The mechanical power is controlled by opening or closing valves regulation water flow. When more water passes through the turbine mechanical output on the shaft of the turbine increases. A transient droop compensator should be included in the speed regulator to improve the stability of the plant. The transfer function of transient droop compensation can be written as [37]:

$$
G_{C}(s)=\frac{1+T_{R} s}{1+\alpha T_{R} s}
$$

where $\alpha=R_{T} / R_{P}$ is slopes ratio and $T_{R}$ is reset time or dashpot constant in sec and both of them is dependent on the $T_{W}$ [38]. $R_{T}$ is temporary droop parameter and $R_{P}$ is permanent governor speed regulation parameter. $R_{T}$ can range from 0.01 to 1.2 and $R_{P}$ is usually equal to 0.05 [39].

$$
\begin{gathered}
T_{R}=T_{W}\left[5-0.5\left(T_{W}-1\right)\right] \\
R_{T}=\frac{T_{W}}{T_{M}}\left[2.3-0.15\left(T_{W}-1\right)\right]
\end{gathered}
$$

\section{Excitation System}

Supply and set direct current excitation winding of synchronous machine is main task of the excitation system. Also, by controlling the excitation voltage can control the voltage and reactive power transfer and enhance system stability and the proper functioning of a system of power. Generator excitation systems, voltage stabilizers and control reactive power and a role in the stability of the generator in case of fault or transient state. Excitation system to improve transient stability should quickly respond to disturbances and to enhance the stability of small disturbances should apply appropriate signal to excitation. The excitation system is represented by a first order model. The IEEE Type-ST1 excitation system as shown in Figure 2 is considered in this paper. It can be described as:

$$
G_{V}(s)=\frac{K_{A}}{1+T_{A} s}
$$

where, $\mathrm{K}_{\mathrm{A}}$ and $\mathrm{T}_{\mathrm{A}}$ are the gain and time constant of the excitation system respectively, $U_{R}$ is the reference voltage, $\mathrm{U}_{\mathrm{S}}$ is PSS output [40]:

$$
\begin{gathered}
\frac{d}{d t} E_{F}=-\frac{1}{T_{A}} E_{F}+\frac{K_{A}}{T_{A}}\left(U_{R}-U_{T}+U_{S}\right) \\
U_{A M I N} \leq E_{F} \leq U_{A M A X}
\end{gathered}
$$

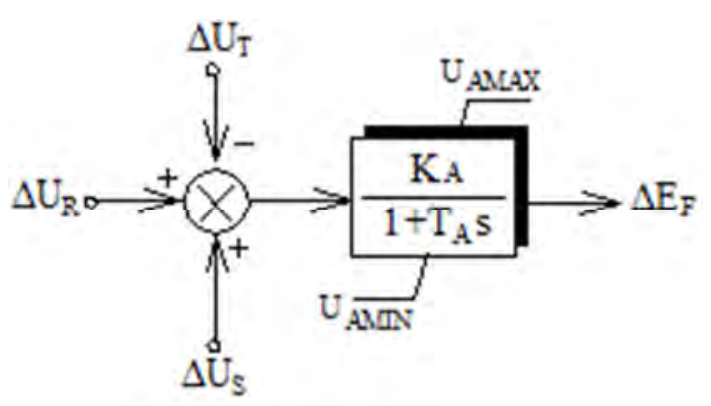

Figure 2. Excitation system.

\section{Power System Stabilizer}

To eliminate the oscillations in the transient state in addition to the frequency and voltage control loops, from the additional controller is used [41, 42]. Power system stabilizer (PSS) provides an additional input signal to generate supplementary control signals for the excitation control system in order to damp slow mode oscillations of the power system $[43,44]$. Some commonly used input signals are rotor 
speed deviation, accelerating power, and frequency deviation. The basic function of PSS is producing a component of electrical torque in phase with rotor speed deviations to increase the system positive damping. The conventional leadlag PSS (CPSS) transfer function is given by the following $[45,46]$ :

$$
G_{P}(s)=K_{Q}\left(\frac{T_{Q} s}{1+T_{Q} s}\right)\left(\frac{1+T_{D} s}{1+T_{G} s}\right)
$$

where $T_{Q}$ is the washout time constant and $\mathrm{K}_{\mathrm{Q}}$ is the PSS pure gain. $T_{D}$ is the lead time constant and $T_{G}$ is the lag time constant. The selection of the $\mathrm{T}_{\mathrm{Q}}$ value depends upon the type of mode under study.

\section{Power System Model}

The power system considered in this paper is a singlemachine infinite-bus (SMIB) power system. It consists of a synchronous generator, a hydro turbine, a governor, an IEEE Type ST1 excitation system, a power system stabilizer and a transmission line connected to infinite-bus. The mathematical relationships between incremental power system variables and inputs is shown in Figure 3, where $\delta$ is angle load, $E_{F}$ is field voltage, $\omega_{\mathrm{r}}$ is angular velocity and $\mathrm{E}_{\mathrm{q}}^{\prime}$ is voltage proportional to direct axis flux linkages. Also, $G_{V}(s), G_{P}(s)$ and $G_{R}(s)$ are transfer function of the exciter system, the power system stabilizer and the voltage regulator system. It consists a generating unit with a hydraulic turbine and proposed PSS and PID controller. The governor includes transient drop. The response of a hydraulic unit to speed change is relatively slow. An additional control block by PSS is added to the AVR, and uses stabilizing feedback signal such as shaft speed to change the input signal of the AVR. The parameters are a function of operating point and the loading in a power system in never constant.

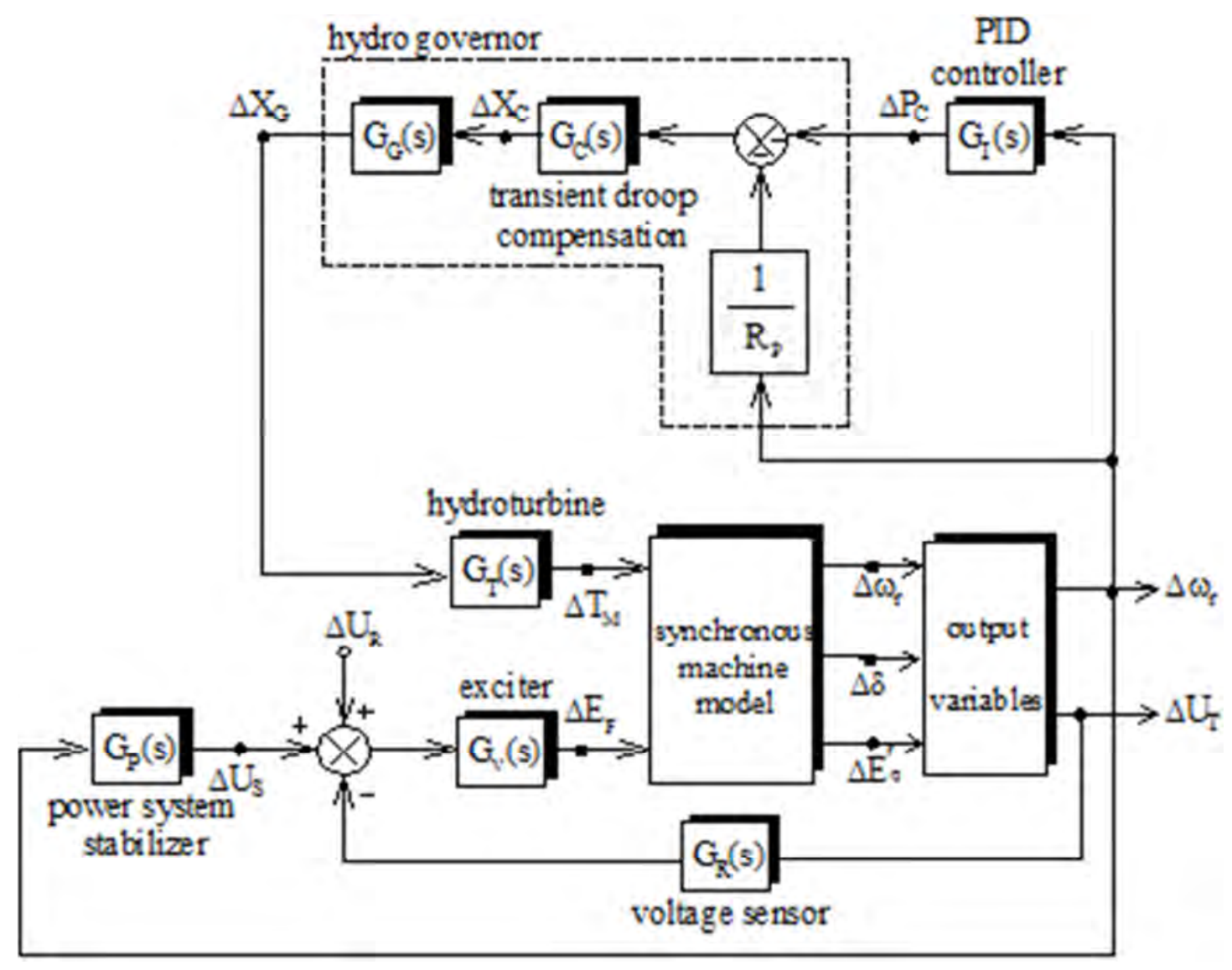

Figure 3. Functional block diagram of power generation and control system.

The primary inputs to the generating unit are the mechanical torque deviation $\left(\Delta \mathrm{T}_{\mathrm{M}}\right)$ and reference terminal voltage deviation $\left(\Delta \mathrm{U}_{\mathrm{R}}\right)$, which there are supplied from a higher level of control. The prime mover (hydro turbine) output affects the input $\mathrm{T}_{\mathrm{M}}$ in the model of the synchronous machine. The primary inputs to the generating unit are $\Delta \mathrm{T}_{\mathrm{R}}$ and $\Delta \mathrm{U}_{\mathrm{R}}$, which there are supplied from a higher level of control.
Small signal stability is best analyzed by linearizing the hydro-turbine governing system differential equations about equilibrium operating point. The system has a multi-input multi-output structure and the use of state space models is a good approach for modeling and control. A simple statespace model of a hydro power plant connected as singlemachine infinite-bus with nine state variable and two inputs is given as follows: 


$$
\begin{gathered}
\frac{d}{d t} \Delta X=A \Delta X+B \Delta U \\
\Delta Y=C \Delta X
\end{gathered}
$$

where A and B are the system matrix and input matrix respectively. The state vector and input vector are given by:

$$
\begin{aligned}
& X=\left[\begin{array}{lllllll}
\delta & \omega_{r} & E_{q}^{\prime} & E_{F} & T_{M}^{\prime} & X_{G} & X_{C}^{\prime}
\end{array}\right]^{T} \\
& X=\left[\begin{array}{ll}
U_{R} & P_{C}
\end{array}\right]^{T}
\end{aligned}
$$

where the changes of the $\mathrm{T}_{M}^{\prime}$ and $\mathrm{X}_{\mathrm{C}}^{\prime}$ are given by:

$$
\begin{gathered}
\Delta T_{M}^{\prime}=2 \Delta X_{G}+\Delta T_{M} \\
\Delta X_{C}^{\prime}=\Delta X_{C}-\frac{1}{\alpha}\left(\frac{-1}{R_{P}} \Delta \omega_{r}-\Delta P_{C}\right)
\end{gathered}
$$

\section{Simulation Results}

In this section the dynamic behavior of the SMIB power system equipped with a hydro turbine for different load variations is examined using of eigenvalues analysis. Simulation results show that the dynamic behavior response. Key parameters of the single-machine infinite-bus power system and three different loading conditions are listed in Table 1. Table 2 depicts the constants $\mathrm{K}$ of the power system under study for various operating conditions. The eigenvalues of the power system equipped with the hydro turbine for various operating conditions are summarized in Tables 3,4 and 5. The values of damping coefficient corresponding to each electromechanical mode is represented in square bracket. The deviation of the load angle without controller with step changes in load disturbance at nominal loading is presented in Figure 4. From these figures, the output response without controller is highly oscillatory, which is not satisfactory.

Table 1. SMIB power system parameters.

\begin{tabular}{ll}
\hline Synchronous generator & $\mathrm{J}_{\mathrm{M}}=9.26, \mathrm{X}_{\mathrm{d}}^{\prime}=0.19, \mathrm{X}_{\mathrm{d}}=0.973, \mathrm{X}_{\mathrm{q}}=0.55, \mathrm{~T}_{\mathrm{do}}^{\prime}=7.76, \mathrm{~K}_{\mathrm{D}}=0, \omega_{\mathrm{b}}=120 \pi, \mathrm{K}_{\mathrm{R}}=1, \mathrm{~T}_{\mathrm{R}}=0$ \\
Excitation system & $\mathrm{K}_{\mathrm{A}}=50, \mathrm{~T}_{\mathrm{A}}=0.05$ \\
Hydro turbine & $\mathrm{T}_{\mathrm{W}}=4, \mathrm{~T}_{\mathrm{G}}=0.2, \mathrm{R}_{\mathrm{P}}=0.05, \mathrm{R}_{\mathrm{T}}=0.7991, \mathrm{~K}_{\mathrm{G}}=1$ \\
& $\mathrm{R}_{\mathrm{E}}=-0.034, \mathrm{X}_{\mathrm{E}}=0.997$ \\
Transmission line & Normal load $\left(\mathrm{P}_{\mathrm{EO}}=1, \mathrm{Q}_{\mathrm{EO}}=0.015, \mathrm{U}_{\mathrm{TO}}=1.05\right)$ \\
& Heavy load $\left(\mathrm{P}_{\mathrm{EO}}=1.1, \mathrm{Q}_{\mathrm{EO}}=0.4, \mathrm{U}_{\mathrm{TO}}=1.05\right)$ \\
Different loading conditions & Light load $\left(\mathrm{P}_{\mathrm{EO}}=0.3, \mathrm{Q}_{\mathrm{EO}}=0.1, \mathrm{U}_{\mathrm{TO}}=1.05\right)$ \\
& $\mathrm{K}_{\mathrm{Q}}=22.7119, \mathrm{~T}_{\mathrm{Q}}=5, \mathrm{~T}_{\mathrm{D}}=0.2715, \mathrm{~T}_{\mathrm{L}}=0.1$ \\
Power system stabilizer & $\mathrm{G}_{\mathrm{L}}=0.249, \mathrm{~B}_{\mathrm{L}}=0.262$ \\
\hline
\end{tabular}

Table 2. Constants $K$ for different loading conditions.

\begin{tabular}{llll}
\hline \multirow{2}{*}{$\begin{array}{l}\text { Constants } \\
\text { K }\end{array}$} & \multicolumn{3}{l}{ Different loading conditions } \\
\cline { 2 - 4 } & Nominal loading & Heavy loading & Light loading \\
\hline $\mathrm{K}_{1}$ & 0.5441 & 0.2140 & 0.5393 \\
$\mathrm{~K}_{2}$ & 1.2067 & 1.1685 & 0.4823 \\
$\mathrm{~K}_{3}$ & 0.6584 & 0.6554 & 0.6584 \\
$\mathrm{~K}_{4}$ & 0.6981 & 0.6254 & 0.1449 \\
$\mathrm{~K}_{5}$ & -0.0955 & -0.1404 & 0.0015 \\
$\mathrm{~K}_{6}$ & 0.8159 & 0.8254 & 0.8757 \\
\hline
\end{tabular}

Table 3. System modes in nominal loading for different states.

\begin{tabular}{lll}
\hline $\begin{array}{l}\text { Without PSS and } \\
\text { LFC }\end{array}$ & $\begin{array}{l}\text { With LFC and without } \\
\text { PSS }\end{array}$ & $\begin{array}{l}\text { With PSS and } \\
\text { LFC }\end{array}$ \\
\hline $0.2958 \pm \mathrm{j} 4.9573$ & $0.3639 \pm \mathrm{j} 3.2869$ & $-2.6135 \pm \mathrm{j} 3.9309$ \\
{$[-0.0596]$} & {$[-0.1100]$} & {$[+0.5537]$} \\
$-10.3936 \pm \mathrm{j} 3.2825$ & $-10.4031 \pm \mathrm{j} 4.9080$ & $-2.9051 \pm \mathrm{j} 7.6334$ \\
& -5.1204 & -19.0882 \\
& -0.4969 & -5.0682 \\
& -0.0045 & -0.4965 \\
0 & -0.2055 \\
& & -0.0045 \\
\hline
\end{tabular}

Table 4. System modes in light loading for different states.

\begin{tabular}{lll}
\hline $\begin{array}{l}\text { Without PSS and } \\
\text { LFC }\end{array}$ & $\begin{array}{l}\text { With LFC and } \\
\text { without PSS }\end{array}$ & With PSS and LFC \\
\hline$-0.0054 \pm \mathrm{j} 4.6785$ & $0.0744 \pm \mathrm{j} 4.6227$ & $-0.8947 \pm \mathrm{j} 4.7620$ \\
{$[+0.0012]$} & {$[-0.0161]$} & {$[+0.1847]$} \\
$-10.0925 \pm \mathrm{j} 3.8420$ & $-10.0924 \pm \mathrm{j} 3.8420$ & $-6.1137 \pm \mathrm{j} 5.3395$ \\
\hline
\end{tabular}

\begin{tabular}{lll}
\hline $\begin{array}{l}\text { Without PSS and } \\
\text { LFC }\end{array}$ & $\begin{array}{l}\text { With LFC and } \\
\text { without PSS }\end{array}$ & With PSS and LFC \\
\hline & -5.1636 & -16.06 \\
& -0.4961 & -5.1207 \\
-0.0045 & -0.4959 \\
0 & -0.2024 \\
& -0.0045 \\
& 0 \\
\hline
\end{tabular}

Table 5. System modes in heavy loading for different states.

\begin{tabular}{lll}
\hline $\begin{array}{l}\text { Without PSS and } \\
\text { LFC }\end{array}$ & $\begin{array}{l}\text { With LFC and } \\
\text { without PSS }\end{array}$ & With PSS and LFC \\
\hline $0.4848 \pm \mathrm{j} 3.6950$ & $0.5622 \pm \mathrm{j} 3.6513$ & $-1.1409 \pm \mathrm{j} 3.2194$ \\
{$[-0.1301]$} & {$[-0.1522]$} & {$[+0.3340]$} \\
$-10.5826 \pm \mathrm{j} 3.6932$ & $-10.5963 \pm \mathrm{j} 3.6944$ & $-4.1409 \pm \mathrm{j} 7.3361$ \\
& -5.1325 & -19.0249 \\
& -0.4949 & -5.0742 \\
& -0.0045 & -0.4939 \\
& 0 & -0.2091 \\
& & -0.0045 \\
& & 0 \\
\hline
\end{tabular}

The electrical torque deviation response in power system equipped with LFC and PSS for step changes in load disturbance is presented in Figure 5. The rotor angle deviation is show in Figure 6, the gate position deviation is show in Figure 7 and the mechanical torque deviation is show in Figure 8. The dynamic response of power system are achieved in nominal loading. 


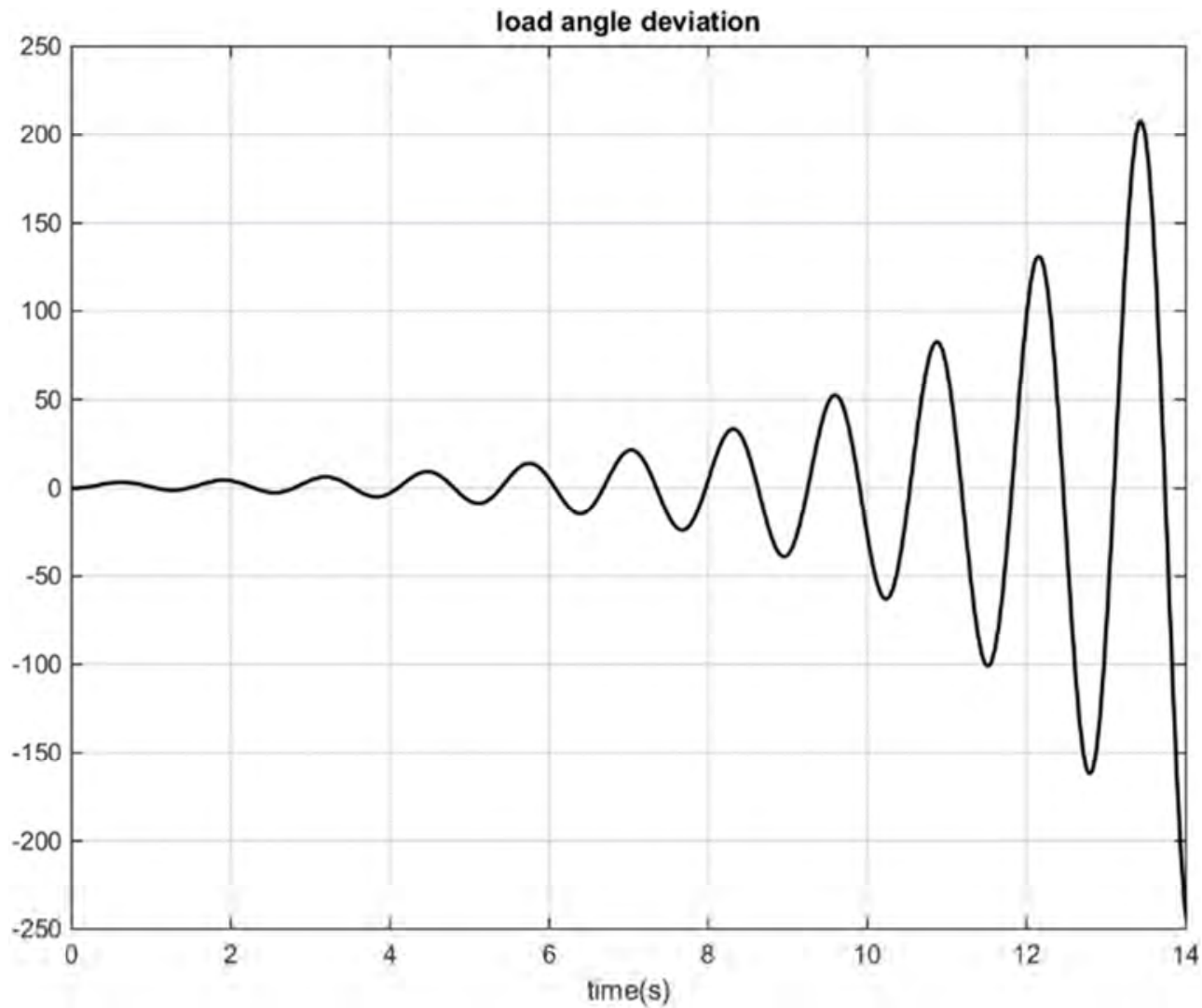

Figure 4. Load angle deviation for power system without PSS.

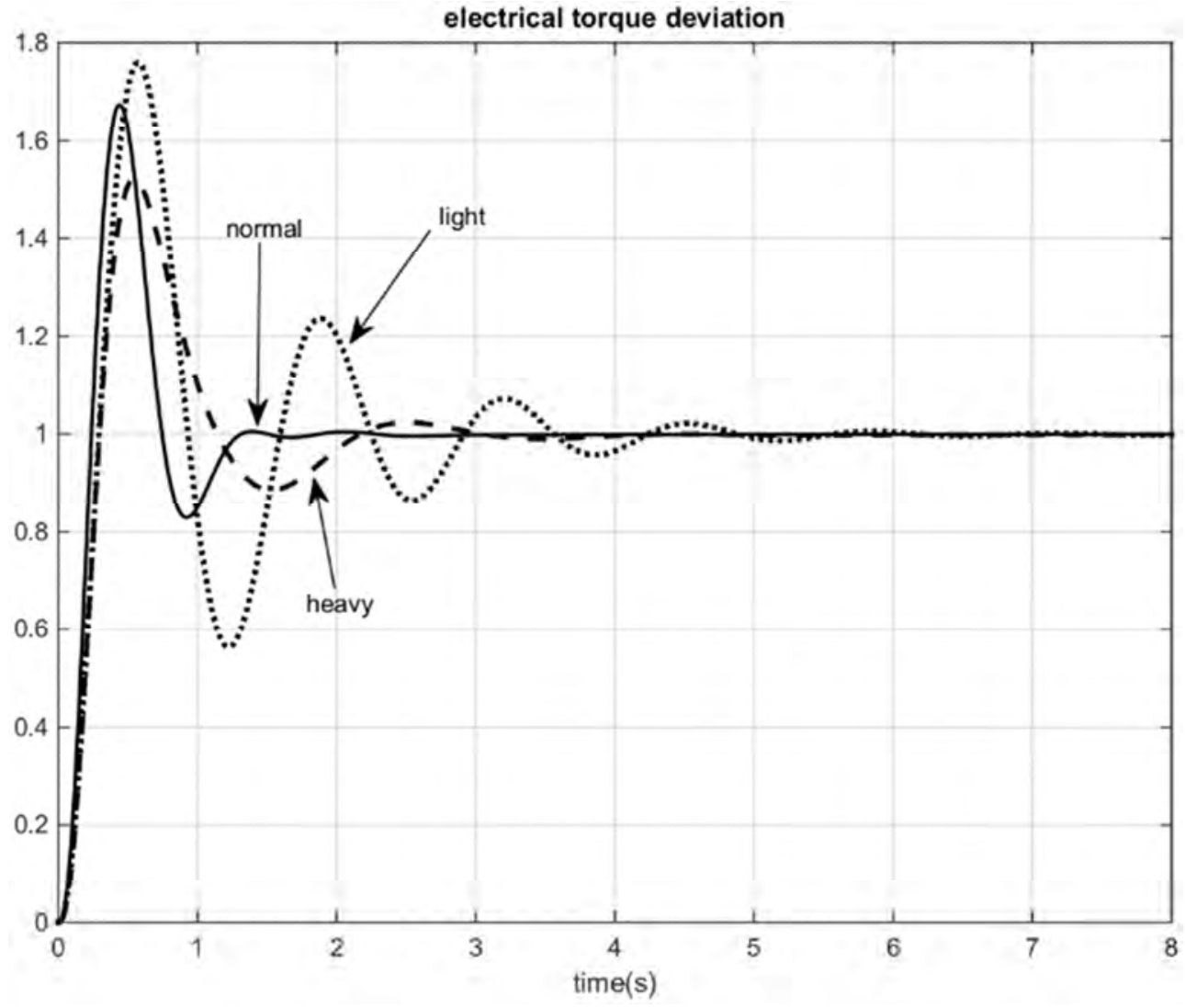

Figure 5. Electrical torque deviation in power system equipped with PSS and LFC. 


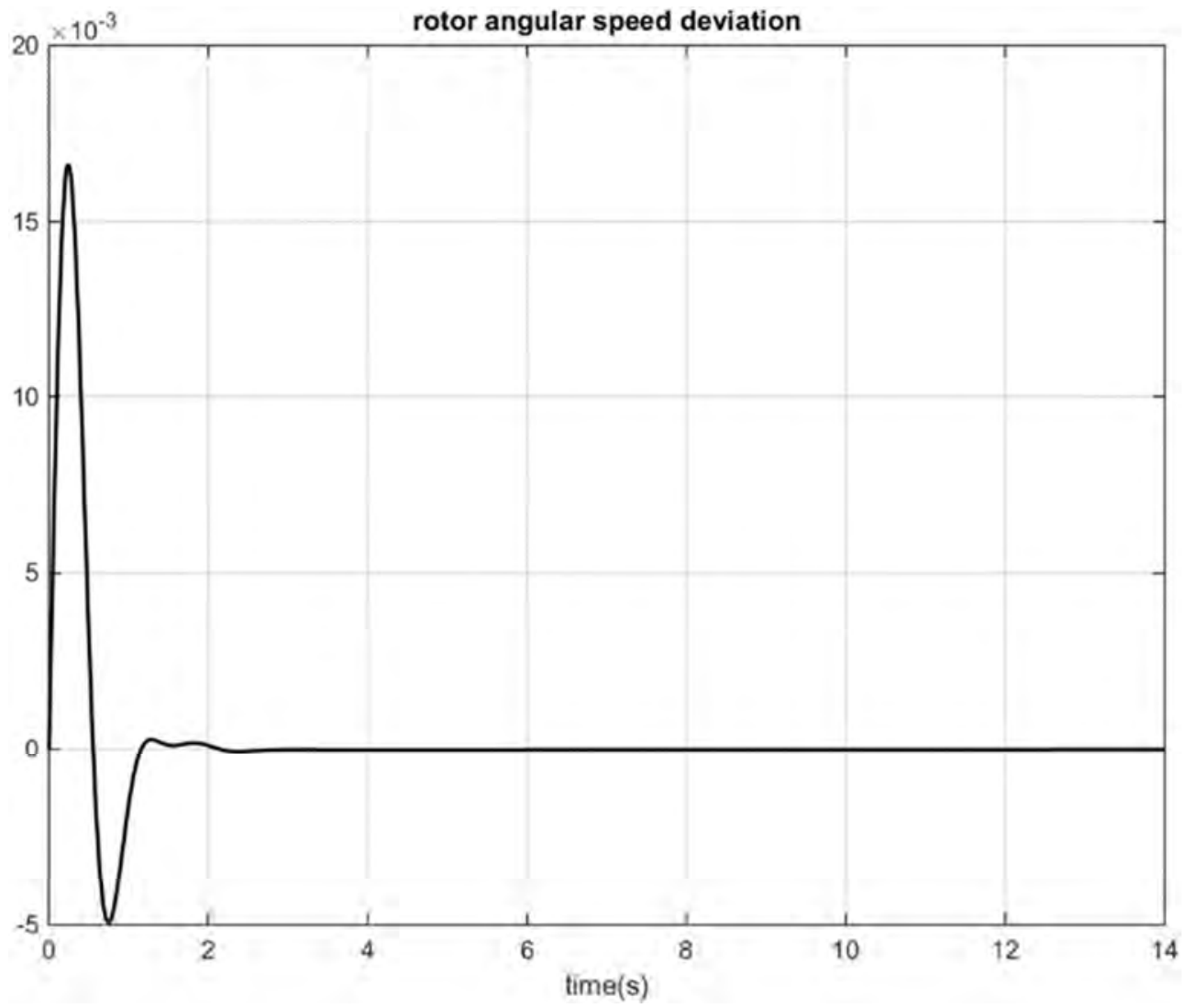

Figure 6. Rotor angular speed deviation in power system equipped with PSS and LFC at nominal loading

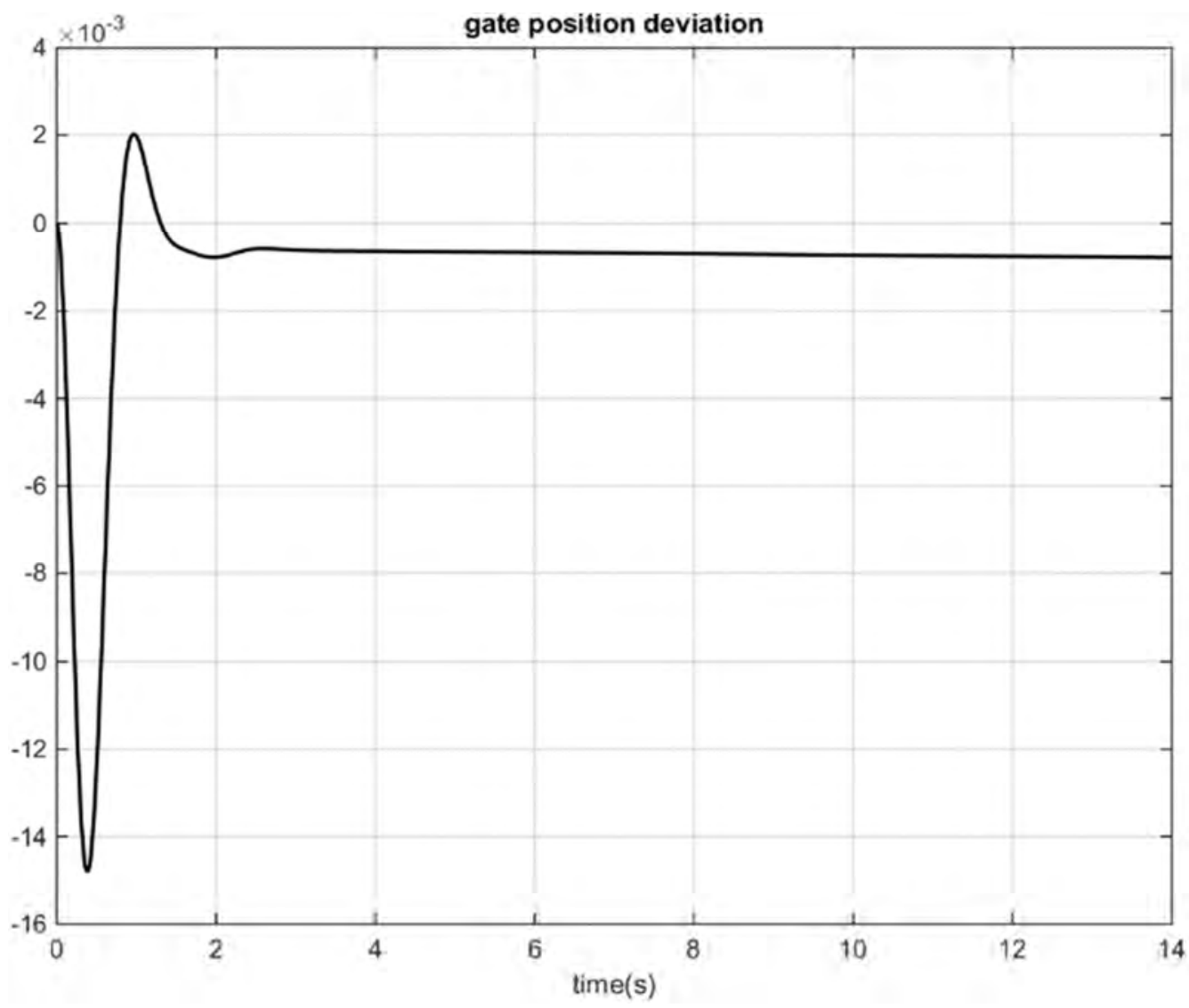

Figure 7. Gate position deviation in power system equipped with PSS and LFC at nominal loading. 


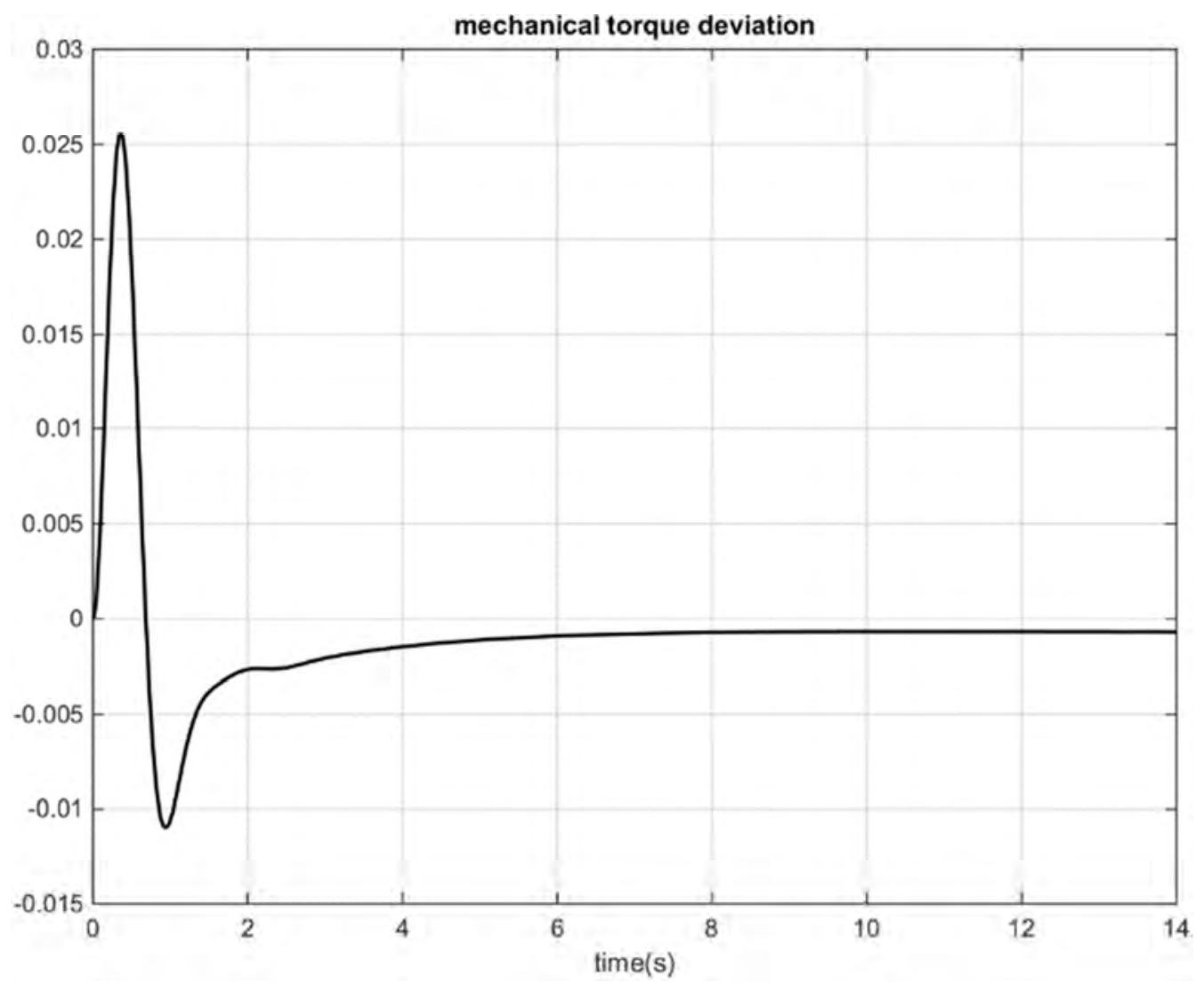

Figure 8. Mechanical torque deviation in power system equipped with PSS and LFC at nominal loading.

\section{Conclusion}

The power and frequency control presents a very important power system dynamic problem. Therefore, LFC is very important task in electrical power system operation for supplying sufficient and reliable electrical power with good quality. In this paper, the effect of PSS on system dynamic performance in power system for single area LFC with hydro turbines will be discussed. A linearized form of nonlinear model was used to design the PSS and LFC in hydro turbine unit. Simulation results show the stability improvement of a hydro power system using PSS.

\section{References}

[1] G. Shahgholian, S. H. Seyed-Hadi Mozafarpoor-Khoshrodi, "Improvement of perturb and observe method for maximum power point tracking in wind energy conversion system using fuzzy controller", Energy Equipment and Systems, Vol. 4, No. 2, pp. 111-122, Autumn 2016.

[2] G. Shahgholian, K. Khani, M. Moazzami, "Frequency control in autanamous microgrid in the presence of DFIG based wind turbine", Journal of Intelligent Procedures in Electrical Technology, Vol. 6, No. 23, pp. 3-12, Autumn 2015.

[3] G. Shahgholian, N. Izadpanahi, "Improving the performance of wind turbine equipped with DFIG using STATCOM based on input-output feedback linearization controller", Energy Equipment and Systems, Vol. 4, No. 1, pp. 63-77, March 2016.
[4] M. Ghasemi, A. R. Roosta, B. Fani, "Coordinated control of FACTS devices by using ADALINE neural network to enhance the transient stability of power system", Journal of Intelligent Procedures in Electrical Technology, Vol. 3, No. 9, pp. 27-40, Spring 2012.

[5] G. Shahgholian, J. Faiz, "An analytical approach to synthesis and modeling of torque control strategy for two-mass resonant systems", International Review of Automatic Control, Vol. 2, No. 4, pp. 459-468, July 2009.

[6] G. Shahgholian, E. Haghjoo, A. Seifi, I. Hassanzadeh, "The improvement DSTATCOM to enhance the quality of power using fuzzy-neural controller", Journal of Intelligent Procedures in Electrical Technology, Vol. 2, No. 6, pp. 3-16, Summer 2011.

[7] M. Fooladgar, E. Rok-Rok, B. Fani, G. Shahgholian, "Evaluation of the trajectory sensitivity analysis of the DFIG control parameters in response to changes in wind speed and the line impedance connection to the grid DFIG", Journal of Intelligent Procedures in Electrical Technology, Vol. 5, No. 20, pp. 37-54, winter 2015.

[8] G. Shahgholian, A. Movahedi, "Power system stabiliser and flexible alternating current transmission systems controller coordinated design using adaptive velocity update relaxation particle swarm optimisation algorithm in multi-machine power system", IET Gener. Transm. Distrib., Vol. 10, No. 8, pp. 1860-1868, May 2016.

[9] G. Shahgholian, Kh. Khani, M. Moazzami, "The Impact of DFIG based wind turbines in power system load frequency control with hydro turbine", Dam and Hedroelectric Powerplant, Vol. 1, No. 3, pp. 38-51, Winter 2015. 
[10] S. Padhan, R. K. Sahu, S. Panda, "Automatic generation control with thyristor controlled series compensator including superconducting magnetic energy storage units", Ain Shams Engineering Journal, Vol. 5, pp. 759-774, 2014.

[11] P. Chauhan, V. Pandya, J. Chauhan, R. Karangia, "Simulation and analysis of ALFC with higher order prime-mover models for single control area", Proceeding of the IEEE/ICEETS, pp. 1084-1089, Nagercoil, April 2013.

[12] S. Pothiya, I. Ngamroo, S. Runggeratigul, P. Tantaswadi, "Design of optimal fuzzy logic based PI controller using multiple tabu search algorithm for load frequency control", International Journal of Control, Automation, and Systems, Vol. 4, No. 2, pp. 155-164, April 2006.

[13] M. Mahdavian, G. Shahgholian, M. Janghorbani, S. Farazpey, M. Azadeh, "Modelling and analysis of a PSS application for LFC in hydro-electric power plant", Proceeding of the IEEE/ECTICON, pp. 1-6, Chiang Mai, Thailand, June/July 2016.

[14] R. K. Khadanga, J. K. Satapathy, "Time delay approach for PSS and SSSC based coordinated controller design using hybrid PSO-GSA algorithm", International Journal of Electrical Power and Energy Systems, Vol. 71, pp. 262-273, 2015.

[15] K. Zare, M. Tarafdar-Hagh, J. Morsali, "Effective oscillation damping of an interconnected multi-source power system with automatic generation control and TCSC", International Journal of Electrical Power and Energy Systems, Vol. 65, pp. 220-230, 2015.

[16] G. Shahgholian, A. Movahedi, J. Faiz, "Coordinated design of TCSC and PSS controllers using VURPSO and genetic algorithms for multi-machine power system stability", International Journal of Control, Automation, and Systems, Vol. 13, No. 2, pp. 398-409, April 2015.

[17] G. Shahgholian, A. Movahedi, "Coordinated design of thyristor controlled series capacitor and power system stabilizer controllers using velocity update relaxation particle swarm optimization for two-machine power system stability", Revue Roumaine Des Sciences Techniques, Vol. 59, No. 3, pp. 291-301, 2014.

[18] IEEE Working Group Report, "Hydraulic turbine and turbine control models for system dynamic studies", IEEE Trans. on Power Systems, Vol. 7, No. 1, pp. 167-179, Feb. 1992.

[19] M. Mahdavian, G. Shahgholian, M. Janghorbani, B. Soltani, N. Wattanapongsakorn, "Load frequency control in power system with hydro turbine under various conditions", Proceeding of the IEEE/ECTICON, pp. 1-5, Hua Hin, Thailand, June 2015 .

[20] A. H. Elbatran, O. B. Yaakob, Y. M. Ahmed, H. M. Shabara, "Operation, performance and economic analysis of low head micro-hydropower turbines for rural and remote areas: A review", Renewable and Sustainable Energy Reviews, Vol. 43, pp. 1624-1635, Nov. 2015.

[21] B. P. Hayes, A. Wilson, R. Webster, S. Z. Djokic, "Comparison of two energy storage options for optimum balancing of wind farm power outputs", IET Generation, Transmission and Distribution, Vol. 10, No. 3, pp. 832-839, March 2016.

[22] H. A. Yousef, K. AL-Kharusi, M. H. Albadi, N. Hosseinzadeh, "Load frequency control of a multi-area power system: An adaptive fuzzy logic approach", IEEE Trans. on Power Systems, Vol. 29, No. 4, pp. 1822-1830, 2014.
[23] H. Bevrani, P. R. Daneshmand, P. Babahajyani, Y. Mitani, T. Hiyama, "Intelligent LFC concerning high penetration of wind power: Synthesis and real-time application", IEEE Trans. on Sustainable energy, Vol. 5, No. 2, pp. 655-662, 2014.

[24] V. Mukherjee, S. P. Ghoshal, "Comparison of intelligent fuzzy based AGC coordinated PID controlled and PSS controlled AVR system", International Journal of Electrical Power and Energy Systems, Vol. 29, No. 9, pp. 679-689, Nov. 2007.

[25] O. P. Malik, Y. Zeng, "Design of a robust adaptive controller for a water turbine governing system", IEEE Trans. on Energy Conversion, Vol. 10, No. 2, pp. 354-359, June 1995.

[26] A. Dysko, W. E. Leithead, J. Reilly, "Enhanced power system stability by coordinated PSS design", IEEE Trans. on Power Systems, Vol. 25, No. 1, pp. 413-422, Feb. 2010.

[27] R. Pradhan, S. Panda, "Application of genetic algorithm based PSS for two - area AGC system in deregulated scenario", IEEE/NABIC, pp. 1207-1212, Coimbatore, Dec. 2009.

[28] S. Sondhi, Y. V. Hote, "Fractional order PID controller for load frequency control", Energy Conversion and Management, Vol. 85, pp. 343-353, 2014.

[29] W. Tan, "Unified tuning of PID load frequency controller for power systems via IMC", IEEE Trans. on Power Systems, Vol. 25, No. 1, pp. 341-350, Feb. 2010.

[30] I. A. Chidambaram, B. Paramasivam, "Optimized loadfrequency simulation in restructured power system with redox flow batteries and interline power flow controller", International Journal of Electrical Power and Energy Systems, Vol. 50, pp. 9-24, Sep. 2013.

[31] K. Natarajan, "Robust PID controller design for hydro turbines", IEEE Trans. on Energy Conversion, Vol. 20, No. 3, pp. 661-667, Sep. 2005.

[32] R. J. Abraham, D. Das, A. Patra, "Effect of TCPS on oscillations in tie-power and area frequencies in an interconnected hydrothermal power system", IET Gener. Transm. Distrib., Vol. 1, No. 4, pp. 632-639, July 2007.

[33] T. Wen, Z. Hongxia, Y. Mei, "Decentralized load frequency control in deregulated environments", International Journal Electric Power and Energy Systems, Vol. 41, No. 1, pp. 16-26, Oct. 2012.

[34] F. J. Garcia, M. K. I. Uemori, J. J. Rocha Echeverria, E. D. Costa Bortoni, "Design requirements of generators applied to low-head hydro power plants", IEEE Trans. on Energy Conversion, Vol. 30, No. 4, pp. 1630-1638, June 2015.

[35] G. Shahgholian, "PID controller design for load-frequncy control in power system with hydro-turbine includes trinsient droop compensation", Dam and Hedroelectric Powerplant, Vol. 2, No. 5, pp. 50-64, 2015 (in Persian).

[36] P. Bhatt, S. P. Ghoshal, R. Roy, "Load frequency stabilization by coordinated control of thyristor controlled phase shifters and superconducting magnetic energy storage for three types of interconnected two-area power systems", Electrical Power and Energy Systems, Vol. 32, pp. 1111-1124, 2010.

[37] G. Shahgholian, P. Shafaghi, H. Mahdavi-Nasab, "A comparative analysis and simulation of ALFC in single area system for different turbines", Proceeding of the IEEE/ICECT, Kuala Lumpur, Malaysia, 2010. 
[38] P. Bhatt, S. P. Ghoshal, R. Roy, "Coordinated control of TCPS and SMES for frequency regulation of interconnected restructured power systems with dynamic participation from DFIG based wind farm", Renewable Energy, Vol. 40, pp. 40$50,2012$.

[39] E. J. Oliveira, L. M. Honorio, A. H. Anzai, L. W. Oliveira, E. B. Costa, "Optimal transient droop compensator and PID tuning for load frequency control in hydro power systems", International Journal of Electrical Power and Energy Systems, Vol. 68, pp. 345-355, June 2015.

[40] G. Shahgholian, "Development of state space model and control of the STATCOM for improvement of damping in a single-machine infinite-bus", International Review of Electrical Engineering, Vol. 4, No. 6, pp. 1367-1375, Nov./ Dec. 2009.

[41] G. Shahgholian, A. Movahedi, "Coordinated control of TCSC and SVC for system stability enhancement using ANFIS method", International Review on Modelling and Simulations, Vol. 4, No. 5, pp. 2367-2375, Oct. 2011.

[42] M. Mahdavian, G. Shahgholian, N. Rasti, "Modeling and damping controller design for static synchronous compensator", Proceeding of the IEEE/ECTICON, pp. 300304, Pattaya, Chonburi, May 2009.

[43] Z. Bouchama, N. Essounbouli, M. N. Harmas, A. Hamzaoui, K. Saoudi, "Reaching phase free adaptive fuzzy synergetic power system stabilizer", International Journal of Electrical Power and Energy Systems, Vol. 77, pp. 43-49, May 2016.

[44] G. Shahgholian, A. Movahedi, "Power system stabiliser and flexible alternating current transmission systems controller coordinated design using adaptive velocity update relaxation particle swarm optimisation algorithm in multi-machine power system", IET Gener. Transm. Distrib., Vol. 10, No. 8, pp. 1860-1868, May 2016.

[45] T. R. Jyothsna, K. Vaisakh, "Effects of strong resonance in tuning of multiple power system stabilizers", IET Gener. Transm. Distrib., Vol. 5, No. 11, pp. 1155-1164, 2011.

[46] G. Shahgholian, J. Faiz, "The effect of power system stabilizer on small signal stability in single-machine infinite-bus", International Journal of Electrical and Engineering, Vol. 4, No. 2, pp. 45-53, 2010. 